\title{
PRÁTICAS DE GESTÃO RELATIVAS À SOCIEDADE EM UM HOSPITAL FILANTRÓPICO: responsabilidade social corporativa ou atendimento a requisitos legais?
}

\author{
Jocias Maier ZANATTA ${ }^{1}$ \\ Martinho Luis KELM ${ }^{2}$ \\ Daniel Knebel BAGGIO ${ }^{3}$
}

\begin{abstract}
${ }^{1}$ Mestre em Desenvolvimento pela Universidade Regional do Noroeste do Estado do Rio Grande do Sul (UNIJUI), Especialista em Gestão Financeira, auditoria e controladoria, Bacharel em Administração. Professor do Curso de Bacharelado em Administração da Sociedade Educacional Três de Maio (SETREM). jociaszanatta@ setrem.com.br

${ }^{2}$ Doutorado em Engenharia da Produção pela Universidade Federal d Santa Catarina - UFSC, Mestrado em Administração pela Universidade Federal do Rio Grande do Sul - UFRGS. martinho@unjui.edu.br
\end{abstract}

${ }^{3}$ Doutorado em Contabilidad y Finanzas pela Universidad de Zaragoza, UNIZAR, Espanha. baggiod@unjui.edu.br

Recebido em: 06/07/2016 - Aprovado em: 19/03/2017 - Disponibilizado em: 01/07/2017

\section{RESUMO}

As práticas de Responsabilidade Social Corporativa - RSC são crescentes nas organizações e tem ganho destaque no cenário mundial, sendo adotada como estratégia de negócio. Em contraponto observa-se a exigência de atendimento a requisitos legais e a adoção de programas de qualidade para fomentar as melhores práticas de gestão. Este artigo busca analisar as práticas de gestão de um hospital filantrópico exigidas para atendimento do critério de sociedade do Programa Gaúcho de Qualidade e Produtividade - PGQP, e fazer uma reflexão destas práticas quanto a sua classificação em RSC ou atendimento a requisitos legais. O estudo de caso teve como premissa a pesquisa documental no relatório de gestão da instituição, pesquisa bibliográfica e pesquisa em artigos científicos. Com a pesquisa concluiuse que as práticas adotadas, em relação a sua classificação, representam 50\% RSC, 33\% atendimento a requisitos legais e $17 \%$ não se enquadram nesta classificação proposta.

Palavras-chave: Programa gaúcho de qualidade e produtividade. Práticas de gestão. Responsabilidade social corporativa. Requisitos legais.

\begin{abstract}
The Corporate Social Responsibility Practices - CSR are increasing in organizations and has highlighted gain on the world stage, being adopted as a business strategy. In contrast observed the requirement of compliance with legal requirements and the adoption of quality programs to promote best management practices. This article examines the management practices of a philanthropic hospital care required for the Gaucho Program society criterion Quality and Productivity - PGQP, and to reflect these practices as their classification in CSR or compliance with legal requirements. The case study was premised on the documentary research on other management report, literature and research in scientific articles. Through research it was concluded that the practices adopted in relation to their classification, account for 50\% CSR, 33\% compliance with legal requirements and 17\% do not fall into this classification proposed.

Keyworks: Gaucho Quality and Productivity Program. Management Practices. Corporate Social Responsibility. Legal Requirements.
\end{abstract}

\section{INTRODUÇÃO}

As práticas de Responsabilidade Social Corporativa - RSC são crescentes em empresas de todo o mundo (ALVARES;
FORMIGONI; ANTUNES, 2014), esta temática tem ganho destaque nos últimos anos e interferindo na concepção das estratégias empresariais (KELM et al. 2014), sendo 
observada, como estratégia para melhoria no desempenho financeiro, resposta a pressões institucionais, discurso de marketing ou atividade pós-lucro (IRIGARAY;VERGARA;SANTOS, 2013).

A RSC deve abordar conjuntamente aspectos econômico-financeiros, sociais e ambientais relacionados com a atividade da organização (XAVIER, 2010), nesse sentido, o Programa Gaúcho da Qualidade e Produtividade - PGQP aborda os assuntos relativos as comunidades influenciadas pela organização, ao analisar as práticas gerenciais relativas ao respeito e tratamento das demandas da sociedade, do meio ambiente e o desenvolvimento social (FNQ, 2011).

No estudo realizado por Álvares, Formigoni e Antunes (2014), analisou as práticas de responsabilidade social corporativa com as quais as empresas brasileiras estão envolvidas, com amostra de 500 empresas agrupadas por área geográfica. Como resultado, observou-se que as variáveis da RSC referentes a práticas ambientais estão ligadas a empresas localizadas na área norte do Brasil, enquanto, as práticas sociais e comunitárias estão ligadas a empresas localizadas principalmente nas regiões sul e nordeste do país.

A tese de França (2012) teve como objetivo analisar o processo de institucionalização das práticas relacionadas ao movimento pela responsabilidade social entre as grandes empresas no Brasil. A pesquisa demonstrou que que os graus de institucionalização das práticas de responsabilidade social são influenciados por três fatores: o faturamento das organizações, a proximidade com o consumidor e o impacto ambiental de suas atividades.

O artigo de Xavier (2010) discorreu sobre as mudanças no mundo empresarial e deu um novo enfoque as práticas voltadas para metas e resultados, a partir da transformação social, que culminou no surgimento da Responsabilidade Social Corporativa. $\mathrm{O}$ estudo concluiu que a Responsabilidade Social Corporativa deve atuar com os padrões éticos, cívicos e sociais, e que em longo prazo traz benefícios às organizações.

Diante do exposto, surge a pergunta norteadora desta pesquisa: As práticas de gestão de um hospital filantrópico relativos ao critério de sociedade do Programa Gaúcho de Qualidade e Produtividade (PGQP) são reflexos da Responsabilidade Social Corporativa ou mero atendimento a requisitos legais?

\section{FUNDAMENTAÇÃO TEÓRICA}

\subsection{Responsabilidade social corporativa}

O termo responsabilidade social corporativa é complexo e de difícil compreensão. Para facilitar o entendimento, pode-se iniciar pela definição de responsabilidade, que pode ser entendida 
como tudo o que lhe é imposto legalmente ou legitimamente e aquilo que se compromete livremente a fazer em termos de produto ou comportamento e sobre elementos de seu contexto que possam impactá-la.

Esta temática nos remete ao paradoxo existente entre a responsabilidade social e o atendimento a requisitos legais ou obrigatórios. Para os economistas, a responsabilidade social não é unânime (ZYLBERSZTAJN, 2002), onde a missão social da empresa é a de gerar o maior lucro possível, dentro das regras da sociedade (FRIERMAN, 1970). Esta definição está longe de ser infundada, ao analisar a RSC pela ótica dos objetivos empresariais, no entanto, o Banco Mundial amplia esta definição e inclui outros elementos neste contexto, mesmo tratando o tema como Responsabilidade Social Empresarial - RSE:

"RSE é o compromisso empresarial de contribuir para o desenvolvimento econômico sustentável, trabalhando em conjunto com os empregados, suas famílias, a comunidade local e a sociedade em geral para melhorar sua qualidade de vida, de maneira que sejam boas tanto para as empresas como para o desenvolvimento" (BANCO MUNDIAL, 2002).

A solidariedade empresarial é algo que surge para encobrir a lógica capitalista do mercado (DEMO, 2002). Neste contexto empresarial, em um ambiente de concorrência global, as organizações necessitam de constantes adaptações e buscam por estratégias para manter-se competitivas e permanecerem no mercado (SCHIAVONI et al., 2013; TEIXEIRA; MORAES, 2013). Este ambiente competitivo incentiva as organizações a modificar o seu posicionamento e a forma de atuação de mercado, considerando à acelerada dinâmica a qual o mercado está condicionado (SILVA; BALBINO, 2013).

Nas organizações, a responsabilidade legal equivale ao cumprimento das leis e adoção de todas as regulamentações necessárias, e a responsabilidade ética diz respeito às práticas e ações esperadas ou proibidas pela sociedade, relacionadas à honestidade, justiça e direitos (VALADÃO; BORGES; MIRANDA, 2008). Contudo, é aceita a ideia de que na atividade empresarial, alem das dimensões econômica e legal, existe a dimensão ética (MACHADO FILHO; ZYLBERSZTAJN, 2004).

\subsection{Programa gaúcho de qualidade e produtividade}

O PGQP foi criado em 1992, com o objetivo de promover a competitividade do Rio Grande do Sul para melhoria da qualidade de vida das pessoas através da busca da excelência em gestão com foco na sustentabilidade. O programa utiliza-se do Modelo de Excelência da Gestão - MEG da Fundação Nacional da Qualidade - FNQ para disseminar a cultura da excelência para as 
organizações gaúchas. As organizações que aderem a este modelo podem participar no ciclo de avaliações, concorrendo ou não a premiação, que contempla em ordem de importância os níveis de medalha, troféu bronze, troféu prata, troféu ouro ou troféu diamante.

No Rio Grande do Sul, nos últimos 22 anos, participaram do PGQP mais de onze mil organizações, ente iniciativa privada, órgãos públicos e terceiro setor, e cerca de 1,3 milhão de pessoas relacionadas à gestão da qualidade. Esse engajamento dos empresários gaúchos demonstra a importância do prêmio na proposta de desenvolvimento do Estado.

O MEG estrutura-se a partir de onze fundamentos da excelência, que norteiam os critérios de excelência, são eles: Pensamento sistêmico, aprendizado organizacional, cultura da inovação, liderança e constância de propósitos, orientação por processos e informações, visão de futuro, geração de valor, valorização das pessoas, conhecimento sobre o cliente e o mercado, desenvolvimento de parcerias e responsabilidade social (FNQ, 2011). A Figura 1 apresenta os critérios de avaliação, que considera a organização como sistema dinâmico e adaptável ao ambiente externo.
Figura 1 - Modelo de excelência da gestão da FNQ: uma visão sistêmica da gestão organizacional

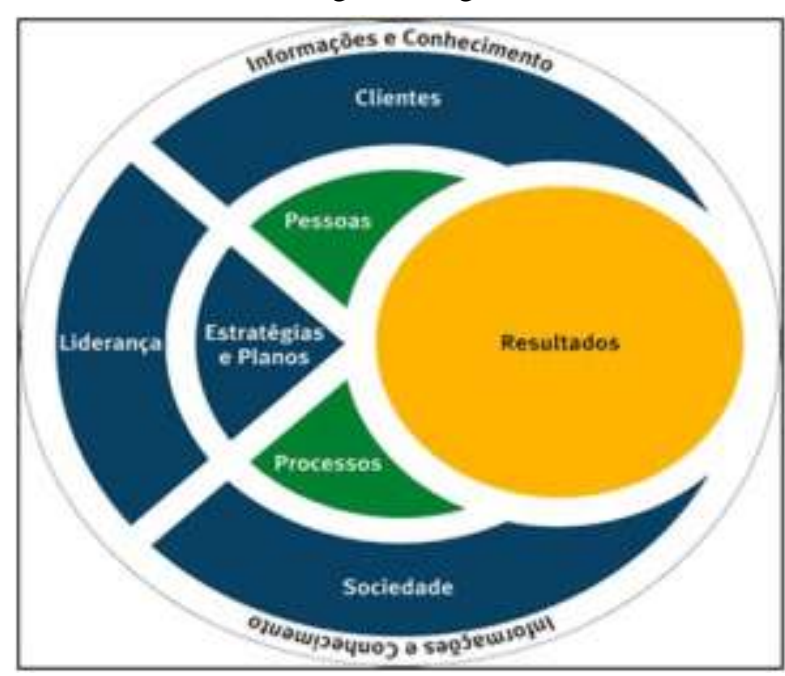

Fonte: Fundação nacional da qualidade (2014)

\section{METODOLOGIA}

Com o intuito de avaliar as práticas de gestão de um hospital filantrópico, realizou-se uma pesquisa descritiva, com abordagem de triangulação entre os métodos quantitativo e qualitativo, e as estratégias de pesquisa utilizadas foram à técnica de estudo de caso, pesquisa bibliográfica, em artigos científicos e documental. A pesquisa descritiva visa identificar, expor e descrever fatos ou fenômenos de determinada realidade, dessa forma foi escolhido como objeto de estudo um hospital filantrópico.

Os dados da pesquisa foram coletados através do relatório de gestão da organização para o PGQP e o referencial teórico foi buscado na literatura e em artigos científicos. Para a análise dos dados foi utilizada a abordagem quantitativa, com a tabulação de dados numéricos através de planilha 
eletrônica, e a abordagem qualitativa para descrever a análise do estudo.

\section{APRESENTAÇÃo E ANÁLISE DOS RESULTADOS}

\subsection{Caracterização da organização objeto do estudo}

O hospital objeto do estudo é filantrópico, religioso, caracterizado como hospital geral e com mais de setenta e cinco anos de atuação. Desde o início o atendimento ao cliente foi marcado por forte humanismo, por gestos de profundo amor e respeito à vida. Aos poucos a instituição foi crescendo e incorporando novos serviços, sendo caracterizado como Hospital Geral e referência regional para diversas especialidades.

O hospital possui uma sólida trajetória no PGQP, que compreende um período de aprendizado superior a uma década, no entanto, apenas em 2012 buscou concorrer a premiação, obtendo em $2014 \quad$ o reconhecimento da medalha bronze. Este fato mostra que a instituição está em constante busca pela excelência na prestação dos serviços, através da melhoria contínua dos processos.

\subsection{Práticas de gestão relativas à sociedade}

O critério quatro do Programa Gaúcho de Qualidade e Produtividade - PGQP, denominado "Sociedade", aborda os processos gerenciais referentes ao respeito e tratamento das demandas da sociedade e do meio ambiente e ao desenvolvimento social das comunidades influenciadas pela organização (FNQ, 2011).

Para atender ao quesito de responsabilidade socioambiental, onde a organização deve preconizar a implementação de processos gerenciais que propiciem a geração de produtos, processos e instalações seguros aos usuários, a população e ao meio ambiente, de forma a fomentar o desenvolvimento social (FNQ, 2011), o Hospital promove as seguintes práticas: Plano de gerenciamento de resíduos de serviço de saúde, terceirização da coleta de resíduos hospitalares, plano de marketing, acompanhamento de normas e resoluções, separação de resíduos recicláveis, descarte de equipamentos eletrônicos, destinação do óleo de cozinha a entidades e integração de novos colaboradores.

$\mathrm{O}$ atendimento do quesito de desenvolvimento social, que aborda a implementação de processos gerenciais que contribuam para estimular o desenvolvimento social e fortalecimento da comunidade (FNQ, 2011), o hospital desenvolve as seguintes práticas: Pesquisa de satisfação dos clientes, participação nos conselhos municipais de saúde e de assistencial social e nas conferências municipais de saúde, projeto de doação de sangue, projeto amor de mãe e acompanhamento a pacientes pós-alta. 
O Quadro 1 apresenta as práticas de gestão relativas a sociedade identificadas no hospital através da análise de seu relatório de gestão para o PGQP:

Quadro 1 - Práticas de gestão dos critérios de responsabilidade ambiental e desenvolvimento sustentável

Fonte: Dados da pesquisa (2015)

\begin{tabular}{|c|c|c|c|}
\hline \multicolumn{2}{|c|}{ Critérios } & \multirow{2}{*}{$\begin{array}{l}\text { Questão } \\
\text { a) Como são identificados os aspectos e tratados os } \\
\text { impactos sociais e ambientais negativos de seus produtos, } \\
\text { processos e instalações? }\end{array}$} & \multirow{2}{*}{$\begin{array}{l}\text { Prática Identificada } \\
\text { Plano de Gerenciamento de Resíduos de Serviço } \\
\text { de Saúde, Contrato Terceirizado para destinação } \\
\text { dos Resíduos Hospitalares. }\end{array}$} \\
\hline \multirow{4}{*}{4.1} & \multirow{4}{*}{ 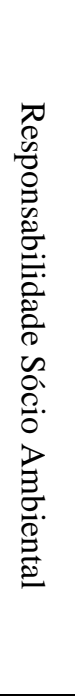 } & & \\
\hline & & $\begin{array}{l}\text { b) Como os impactos sociais e ambientais dos produtos, } \\
\text { processos e instalações e outras informações relativas à } \\
\text { responsabilidade socioambiental consideradas relevantes } \\
\text { são comunicados à sociedade, incluindo as comunidades } \\
\text { potencialmente impactadas? }\end{array}$ & Plano de Marketing. \\
\hline & & $\begin{array}{l}\text { c) Como são Identificados e analisados os requisito } \\
\text { legais, regulamentares e contratuais aplicáveis à } \\
\text { organização e implementadas ações de melhoria visando } \\
\text { ao seu pleno atendimento? }\end{array}$ & $\begin{array}{l}\text { Acompanhamento de Normas e Regulações } \\
\text { emitidas pelos Órgãos competentes. }\end{array}$ \\
\hline & & $\begin{array}{l}\text { d) Como a organização seleciona e promove de forma } \\
\text { voluntária ações com vistas ao desenvolvimento } \\
\text { sustentável? }\end{array}$ & $\begin{array}{l}\text { Programa de separação de Resíduos } \\
\text { Recicláveis, Programa 5S, Descarte de } \\
\text { Equipamentos Eletrônicos, Destinação de Óleo } \\
\text { de Cozinha a entidades carentes, Integração de } \\
\text { Novos Colaboradores. }\end{array}$ \\
\hline \multirow{2}{*}{4.2} & \multirow{2}{*}{ 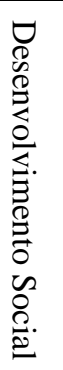 } & $\begin{array}{l}\text { a) Como as necessidades e as expectativas de } \\
\text { desenvolvimento da sociedade, incluindo comunidades } \\
\text { vizinhas às instalações da organização, são identificadas, } \\
\text { analisadas e utilizadas para a definição e a melhoria da } \\
\text { sua atuação social? }\end{array}$ & $\begin{array}{l}\text { Pesquisa de Satisfação de Clientes, Participação } \\
\text { nos Conselhos Municipais de Saúde e de } \\
\text { Assistência Social e nas Conferências } \\
\text { Municipais de Saúde. }\end{array}$ \\
\hline & & $\begin{array}{l}\text { b) Como a organização direciona esforços para o } \\
\text { fortalecimento da sociedade, incluindo comunidades } \\
\text { vizinhas executando ou apoiando projetos voltados para } \\
\text { o desenvolvimento nacional, regional, local ou setorial? }\end{array}$ & $\begin{array}{l}\text { Projeto de Doação de Sangue, Projeto Amor de } \\
\text { Mãe e Acompanhamento a pacientes pós-alta. }\end{array}$ \\
\hline
\end{tabular}

Os impactos sociais e ambientais de produto, processos e instalações são tratados através do Acompanhamento do Plano de Gerenciamento de Resíduos de Serviços de Saúde. É realizado o levantamento de todas as classes de resíduos gerados pelos serviços da instituição, são estabelecidas medidas técnicas para identificação, segregação, acondicionamento e destinação final, bem como, realização de treinamentos com os colaboradores para esclarecimento das normas vigentes. Esta prática trata os impactos sociais e ambientais de forma proativa e abrange todos os serviços do hospital. A coleta e destinação final dos resíduos decorrentes da atividade hospitalar são realizadas através de um contrato de prestação de serviço com empresa terceirizada, com a finalidade de prevenir situações adversas à sociedade e ecossistemas.

A comunicação dos impactos sociais e ambientais relevantes às partes interessadas ocorre através do plano de marketing, que é elaborado e revisado anualmente com o 
auxilio de empresa especializada. Esta prática norteia toda política de comunicação interna e externa da instituição.

Os requisitos legais, regulamentares e contratuais aplicáveis á instituição são acompanhados permanentemente através da assessoria jurídica corporativa, que interage sistematicamente com a direção executiva da rede onde dissemina os temas relacionados a cada instituição mantida. Para a área da saúde todos os requisitos legais e regulamentares são analisados e enviados os pareceres para a diretoria local. Da mesma maneira a mantenedora delibera sobre as auditorias externas contábeis e financeiras a fins de garantir a execução dos aspectos legais pertinentes à instituição. O grupo de gestão do hospital realiza a análise da legislação e normas vigentes à organização (portarias regulamentadoras do Ministério da Saúde, Vigilância Sanitária entre outros) e promove a discussão das necessidades de adaptação e impacto financeiro, para deliberar as ações a serem implementadas.

As ações relativas ao desenvolvimento sustentável são selecionadas e promovidas de forma voluntária, através de práticas de gestão específicas. É realizada a separação e classificação dos resíduos não hospitalares, em comum, orgânico e reciclável, onde os materiais são comercializados e os valores arrecadados são destinados a projetos sociais. O Programa 5S, de responsabilidade da comissão da qualidade, também preconiza a otimização de recursos e o aproveitamento dos materiais e equipamentos, onde anualmente é realizado um descarte consciente por cada serviço da instituição, com o objetivo de limpeza e reaproveitamento dos materiais.

O serviço de nutrição realiza a destinação do óleo de cozinha a entidades carentes do município, que o utilizam para fabricar sabão e vendê-lo na comunidade. O programa de integração de novos colaboradores é importante prática para sensibilizar os novos colaboradores quanto ao desenvolvimento sustentável e disseminar as práticas de gestão existentes.

As necessidades e expectativas de desenvolvimento da sociedade são identificadas, analisadas através da pesquisa de satisfação de clientes e a participação ativa no conselho municipal de saúde, assistência social e conferências municipais de saúde. Estas informações coletadas são utilizadas para a definição e a melhoria da atuação social da instituição.

O hospital possui três projetos sociais de grande impacto social e que atendem demandas da sociedade, sendo eles: projeto amor de mãe, projeto de doação de sangue e acompanhamento pós-alta. O projeto amor de mãe aborda temas relacionados à gravidez $\mathrm{e}$ cuidado do bebê, durante o programa é oportunizado as futuras mães palestras e treinamentos sobre diversos assuntos relacionados ao tema, com acompanhamento 
de equipe multiprofissional. Em um serviço hospitalar é crescente e fundamental a utilização de hemocomponentes, em vista disso, é realizado o projeto de Doação de Sangue, com o objetivo de sensibilizar a comunidade e angariar doadores de sangue para aumentar os estoques regionais de hemocomponentes, através de campanhas de doação de sangue dentro do hospital e também com transporte de doadores até o hemocentro. $\mathrm{O}$ acompanhamento a pacientes pós-alta é realizado por uma assistente social e tem o objetivo de acompanhar os pacientes do sistema único de saúde após sua internação, para viabilizar o seu tratamento, vivenciar a situação social em que a família encontra-se, estreitar a relação com a saúde da família e evitar a reinternação do pacientes por mesma patologia.

Através da análise do critério de sociedade do PGQP e as práticas de gestão evidenciadas pela instituição, é possível avaliar se estas práticas são decorrentes de uma RSC ou um atendimento a requisitos legais, conforme ilustrado no Quadro 2:

Quadro 2 - Classificação das práticas de gestão

\begin{tabular}{|l|c|c|c|}
\hline Prática Identificada & $\begin{array}{c}\text { Atendimento } \\
\text { Requisitos } \\
\text { Legais }\end{array}$ & RSC & Outro \\
\hline $\begin{array}{l}\text { Plano de Gerenciamento } \\
\text { de Resíduos de Serviço } \\
\text { de Saúde }\end{array}$ & $\mathrm{x}$ & & \\
\hline $\begin{array}{l}\text { Contrato Terceirizado } \\
\text { para destinação dos } \\
\text { Resíduos Hospitalares }\end{array}$ & $\mathrm{x}$ & & \\
\hline Plano de Marketing & & & \\
\hline $\begin{array}{l}\text { Acompanhamento de } \\
\text { Normas e Regulações } \\
\text { emitidas pelos Órgãos } \\
\text { competentes }\end{array}$ & $\mathrm{x}$ & & \\
\hline
\end{tabular}

\begin{tabular}{|l|l|l|l|}
$\begin{array}{l}\text { Programa de separação } \\
\text { de Resíduos Recicláveis }\end{array}$ & $\mathrm{x}$ & \\
\hline Programa 5S de & & $\mathrm{x}$ & \\
\hline $\begin{array}{l}\text { Descarte } \\
\text { Equipamentos } \\
\text { Eletrônicos }\end{array}$ & $\mathrm{x}$ & \\
\hline $\begin{array}{l}\text { Destinação de Óleo de } \\
\text { Cozinha a entidades } \\
\text { carentes de Novos }\end{array}$ & & $\mathrm{x}$ & \\
\hline $\begin{array}{l}\text { Integração de } \\
\text { Colaboradores }\end{array}$ & $\mathrm{x}$ & \\
\hline $\begin{array}{l}\text { Pesquisa de Satisfação } \\
\text { de Clientes }\end{array}$ & $\mathrm{x}$ & & $\mathrm{x}$ \\
\hline $\begin{array}{l}\text { Participação } \\
\text { Conselhos Municipais }\end{array}$ & & $\mathrm{x}$ & \\
\hline Projetos Sociais & & \\
\hline
\end{tabular}

Fonte: Dados da pesquisa (2015)

Ao classificar a origem das práticas de gestão, observa-se um relativo equilíbrio entre o atendimento a requisitos legais e a RSC, percebe-se que esta classificação na esta evidente para a instituição e algumas práticas não se enquadram nesta análise. A descrição e análise aprofundada das práticas de gestão tiveram inicio apenas com a participação nas etapas de premiação do PGQP, o que reflete a importância deste programa.

A Figura 2 apresenta a classificação das práticas de gestão quanto a sua origem:

Figura 2 - Classificação das práticas de gestão

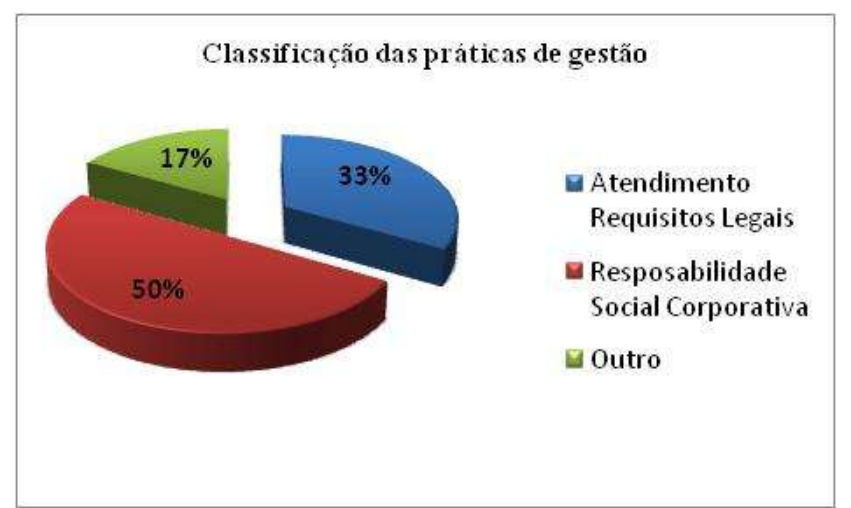

Fonte: Dados da pesquisa (2015)

Apesar da recente participação do hospital na disputa pela premiação do PGQP, 
as práticas de gestão classificadas como RSC representam $50 \%$ do total, o que demonstra que a instituição esta trilhando um caminho para buscar o status de socialmente responsável, o que exige uma análise aprofundada considerando outros fatores. Para Serpa, Ávila e Faria (2010) para uma empresa ser socialmente responsável deve ter bom desempenho econômico, produzir bens ou serviços, gerar empregos e retorno a acionistas, dentro das normas legais e éticas.

As duas práticas (Plano de Marketing e Pesquisa de Satisfação dos Clientes) que não se enquadraram na classificação de RSC ou atendimento de requisitos legais é em decorrência de serem práticas que não tem impacto significativo nestes itens, no entanto, devem ser mantidas e tem importância na gestão do negócio.

\section{CONCLUSÃO}

A RSC e o atendimento de requisitos legais embora sejam opostos, são complementares em determinadas situações, onde uma prática que hoje é considerada RSC pode no futuro tornar-se um requisito legal. A RSC também implica em a empresa seja responsável pelos efeitos de suas atividades e bem-estar de seus empregados, clientes, comunidade local e sociedade (BORGER, 2001; MACHADO FILHO; ZYLBERSZTAJN, 2004).
Durante a pesquisa observou-se que não esta clara para a instituição a definição de RSC, que se confunde com o atendimento de requisitos legais e muitas vezes são levados em consideração apenas os projetos sociais (Amor de Mãe, Doação de Sangue e PósAlta). O PGQP é um importante mecanismo para evidenciar as práticas de gestão relativas a sociedade, através da documentação, análise e discussão das práticas existentes.

As práticas de gestão adotadas para atendimento ao critério de sociedade do PGQP, mesmo tendo a mesma finalidade, não podem ser consideradas em sua totalidade como RSC ou atendimento a requisitos legais. Existe um equilíbrio nesta análise, onde as práticas relativas a projetos sociais e sustentabilidade são consideradas como RSC, e as práticas inerentes a contratos de prestação de serviços e legislação são definidos como atendimento a requisitos legais.

A instituição pesquisada, embora tenha um número considerável de práticas de gestão relativas à sociedade, encontra-se em estágio inicial de RSC e atende a todos os requisitos legais relativos ao serviço hospitalar. Conclui-se que, as práticas de gestão do hospital filantrópico pesquisado, relacionadas ao critério de sociedade do PGQP, em sua maioria, são reflexos da RSC, seguidos pelo atendimento a requisitos legais, no entanto, a descrição das práticas, acompanhamento e aprimoramento são decorrentes da participação da instituição no 
PGQP. Pode-se dizer, que através do PGQP o hospital esta em busca da excelência em gestão e revisa a cada ano suas práticas no quesito sociedade, em paralelo a outros aspectos (indicadores gerenciais) com $\mathrm{O}$ objetivo de ser uma empresa socialmente responsável.

Para estudos futuros, sugere-se que sejam realizadas pesquisas com os demais critérios do PGQP, levando em consideração outros fatores que impactam nas práticas de gestão do hospital.

\section{REFERÊNCIAS BIBLIOGRÁFICAS}

ÁlVAREZ, I. G.; FORMIGONI, H.; ANTUNES, M. T. P. Corporate social responsibility practices at Brazilian firms. Revista de Administração de Empresas, v. 54, n. 1, p. 12-27, 2014.

BANCO MUNDIAL . Public sector roles in strengthening corporate social responsibility: a baseline study. Whashington, 2002.

BORGER, F. Responsabilidade social: efeitos da atuação social na dinâmica empresarial. 2001. Tese (Doutorado) Faculdade de Economia, Administração e Contabilidade da Universidade de São Paulo, São Paulo, São Paulo, Brasil, 2001.

DEMO, Pedro. Solidariedade com efeito de poder. São Paulo: Cortez/Instituto Paulo Freire, 2002. (Coleção Prospectiva, v.6)

FRANÇA, Andressa Silvério Terra. Empresas, empresários e instituições: uma análise de responsabilidade social das empresas do Brasil. 2012. $276 \mathrm{f}$. Tese (Doutorado em Sociologia) - Setor de Ciência
Humana, Letras e Artes, Universidade Federal do Paraná, Curitiba.

FRIEDMAN, M. The social responsibility of business is to increase its profits. New York Times Magazine, setembro, 1970.

FUNDAÇÃO NACIONAL DA QUALIDADE (FNQ). Critérios rumo a excelência. Fundação Nacional da Qualidade: São Paulo, 2011.

\section{. Modelo de excelência da gestão.}

Disponível em:

$<$ http://www.fnq.org.br/avalie-

se/metodologia-meg/modelo-de-excelenciada-gestao>. Acesso em: 02 abr, 2015.

IRIGARAY, H. A. R.; VERGARA, S. C.; SANTOS, M. C. F. Responsabilidade social corporativa: um duplo olhar sobre a Reduc.

Revista de Administração Mackenzie, v. 14, n. 6, p. 82-111, 2013.

KELM, M. L.; RENZ, C. L. S.; ALLEBRANDT, S. L.; SAUSEN, J. O. Institucionalização das iniciativas socioambientais das organizações: interfaces entre a teoria do desenvolvimento social de Habermas e o isomorfismo da teoria institucional. Cadernos EBAPE.BR, v. 12, n. Edição Especial, p. 401-401, 2014.

DOI: http://dx.doi.org/10.1590/167939519097

MACHADO FILHO, C. A. P.; ZYLBERSZTAJN, D. A empresa socialmente responsável: o debate e as implicações.

Revista de Administração, v. 39, n. 3, p. 242-254, 2004.

SCHIAVONI, P. M. B.; MORAES, M. C. B.; CASTRO, A. C.; SANTOS, J. N.

Stakeholders: principais abordagens. Revista de Ciências da Administração, v. 15, n. 37, p. 187-197, 2013.

http://dx.doi.org/10.5007/2175$\underline{8077.2013 v 15 n 37 p 187}$

SERPA, D. A. F.; AVILA, M.; FARIA, M. D. Efeitos da responsabilidade social corporativa 
na intenção de compra e no benefício percebido pelo consumidor: um estudo experimental. Revista de Administração, v. 45, n. 3, art. 6, p. 285-296, 2010.

SILVA, M. E.; BALBINO, D. P. Criando vantagem competitiva sustentável: a responsabilidade socioambiental empresarial à luz da visão baseada em recursos. Revista Ibero-Americana de Estratégia, v. 12, n. 1, p. 29-53, 2013.

SOARES, A. C.; SOARES, E. C. Qualidade ofertada e demandada: as certificações da qualidade ISO e PGQP em uma instituição de ensino de Pelotas/RS. NAVUS - Revista de Gestão e Tecnologia, v. 4, n. 2, p. 127-142, 2014.

TEIXEIRA, M. G. C.; MORAES, I. B. O diálogo com stakeholders na teoria e na prática: análise da relação de uma empresa pública do setor industrial com seus stakeholders, para a construção de uma política de responsabilidade social. Revista de Administração da UFSM, v. 6, n. Edição Especial, p. 843-859, 2013. http://dx.doi.org/10.5902/198346598636

VALADÃO JÚNIOR, V. M.; BORGES, J. F.; MIRANDA, R. O discurso das Fundações Corporativas: caminhos de uma "Nova" Filantropia?. GESTÃO.Org - Revista Eletrônica de Gestão Organizacional, v. 6, n. 2, p. 211-230, 2008.

XAVIER, A. V. Responsabilidade Social Corporativa: um enfoque multidisciplinar no contexto globalizado. Desenvolvimento em Questão, v. 8, n. 16, p. 131-158, 2010.

ZYLBERSZTAJN, D. Organização ética: um ensaio sobre comportamento e estrutura das organizações. Revista de Administração

Contemporânea, v. 6, n. 2, p. 123-143, 2002. 